\title{
Mycorrhizal Associations and Trophic Modes in Coexisting Orchids: An Ecological Continuum between Auto- and Mixotrophy
}

\author{
Hans Jacquemyn ${ }^{\text {** }}$, Michael Waud ${ }^{1}$, Rein Brys ${ }^{2}$, Félix Lallemand ${ }^{3}$, \\ Pierre-Emmanuel Courty ${ }^{4}$, Alicja Robionek ${ }^{5,6}$ and Marc-André Selosse ${ }^{3,6 * t}$
}

${ }^{1}$ Plant Conservation and Population Biology, Department of Biology, KU Leuven, Leuven, Belgium, ${ }^{2}$ Research Institute for Forest and Nature, Geraardsbergen, Belgium, ${ }^{3}$ Institut de Systématique, Évolution, Biodiversité, UMR 7205, CNRS, MNHN, UPMC, EPHE, Muséum National d'Histoire Naturelle, Sorbonne Universités, Paris, France, ${ }^{4}$ Department of Biology, University of Fribourg, Fribourg, Switzerland, ${ }^{5}$ The Laboratory of Freshwater Ecology, Department of Plant Ecology, University of Gdańsk, Gdańsk, Poland, ${ }^{6}$ Department of Plant Taxonomy and Nature Conservation, University of Gdańsk, Gdańsk, Poland

OPEN ACCESS

Edited by: Essaid Ait Barka, University of Reims

Champagne-Ardenne, France

Reviewed by: Richard S. Winder, Natural Resources Canada, Canada Raffaella Balestrini, Consiglio Nazionale delle Ricerche (CNR), Italy

*Correspondence:

Hans Jacquemyn

hans.jacquemyn@kuleuven.be

Marc-André Selosse

ma.selosse@wanadoo.fr

${ }^{\dagger}$ These authors have contributed equally to this work.

Specialty section: This article was submitted to Plant Microbe Interactions, a section of the journal Frontiers in Plant Science

Received: 17 June 2017 Accepted: 14 August 2017 Published: 29 August 2017

Citation: Jacquemyn $H$, Waud $M$, Brys $R$ Lallemand F, Courty P-E, Robionek A and Selosse M-A (2017) Mycorrhizal

Associations and Trophic Modes in Coexisting Orchids: An Ecological Continuum between Autoand Mixotrophy.

Front. Plant Sci. 8:1497. doi: 10.3389/fpls.2017.01497
Two distinct nutritional syndromes have been described in temperate green orchids. Most orchids form mycorrhizas with rhizoctonia fungi and are considered autotrophic. Some orchids, however, associate with fungi that simultaneously form ectomycorrhizas with surrounding trees and derive their carbon from these fungi. This evolutionarily derived condition has been called mixotrophy or partial mycoheterotrophy and is characterized by ${ }^{13} \mathrm{C}$ enrichment and high $\mathrm{N}$ content. Although it has been suggested that the two major nutritional syndromes are clearly distinct and tightly linked to the composition of mycorrhizal communities, recent studies have challenged this assumption. Here, we investigated whether mycorrhizal communities and nutritional syndromes differed between seven green orchid species that co-occur under similar ecological conditions (coastal dune slacks). Our results showed that mycorrhizal communities differed significantly between orchid species. Rhizoctonia fungi dominated in Dactylorhiza sp., Herminium monorchis, and Epipactis palustris, which were autotrophic based on ${ }^{13} \mathrm{C}$ and $\mathrm{N}$ content. Conversely, Liparis loeselii and Epipactis neerlandica associated primarily with ectomycorrhizal fungi but surprisingly, ${ }^{13} \mathrm{C}$ and $\mathrm{N}$ content supported mixotrophy only in $\mathrm{E}$. neerlandica. This, together with the finding of some ectomycorrhizal fungi in rhizoctonia-associated orchids, suggests that there exists an ecological continuum between the two syndromes. The presence of a large number of indicator species associating with individual orchid species further confirms previous findings that mycorrhizal fungi may be important factors driving niche-partitioning in terrestrial orchids and therefore contribute to orchid coexistence.

\section{Keywords: carbon nutrition, coexistence, mycoheterotrophy, orchids, partial mycoheterotrophy, rhizoctonia}

\section{INTRODUCTION}

Since the early discoveries that orchids significantly rely on mycorrhizal fungi for seed germination and seedling establishment (Bernard, 1899; Burgeff, 1909), it has become increasingly clear that mycorrhizal fungi play an important role in carbon nutrition of orchids and therefore also in their population dynamics and spatial distribution (McCormick and Jacquemyn, 2014). In the early 
stages of orchid development, fungi provide carbon to orchid seeds, which due to their tiny size lack the necessary nutritional resources to develop (Smith and Read, 2008; Dearnaley et al., 2016). Although several orchid species belonging to various, unrelated genera remain achlorophyllous at adulthood (Merckx, 2013) and maintain a continual reliance on fungal carbon (a nutrition called mycoheterotrophy), most orchids are green at adulthood and become photosynthetic after the first green leaves have developed. However, the extent to which mycorrhizal fungi contribute to carbon nutrition of adult green orchids remains unclear.

In general, two main nutritional syndromes have been described for adult green orchids (Selosse et al., 2016). In some green orchid species, often related to the above-mentioned achlorophyllous species, a partly heterotrophic syndrome has been described, called partial mycoheterotrophy or mixotrophy (Selosse and Roy, 2009; Hynson et al., 2013). Such species often grow in closed forest habitats with limited light-availability and associate with the same fungal guilds as achlorophyllous species, most often fungi that form ectomycorrhizae on surrounding trees (Bidartondo et al., 2004; Selosse et al., 2004). Direct evidence for mixotrophy comes from three observations. First, such orchids display reduced photosynthetic ability either due to intrinsic limitation (Girlanda et al., 2006; Cameron et al., 2008) or to environmental conditions (Julou et al., 2005). Secondly, achlorophyllous variants can survive in nature (Roy et al., 2013; Shefferson et al., 2016). Third, these orchids have ${ }^{13} \mathrm{C}$ and ${ }^{15} \mathrm{~N}$ natural abundances and total $\mathrm{N}$ content that are intermediate between those of autotrophic plants and achlorophyllous orchids (Abadie et al., 2006; Hynson et al., 2013, 2016). The latter are highly enriched in both isotopes and have a high $\mathrm{N}$ content (Trudell et al., 2003; Hynson et al., 2016), likely because similar features characterize the biomass of the ectomycorrhizal fungi supporting them (Hynson et al., 2013). Thus, mixotrophic orchids combine photosynthesis and heterotrophic nutrition on ectomycorrhizal fungi.

The second syndrome, called autotrophy, concerns the vast majority of orchids that associate with basidiomycetous fungi collectively called 'rhizoctonias.' Rhizoctonia fungi belong to Tulasnellaceae, Ceratobasidiaceae (two families of the order Cantharellales), and Serendipitaceae (Sebacinales; Dearnaley et al., 2012) and behave as saprotrophs in the soil or as endophytes in non-orchid plants (Girlanda et al., 2011; Selosse and Martos, 2014). Based on in vitro evidence of mycorrhizal C flow observed in one species (Cameron et al., 2008), and on the fact that rhizoctonia-associated orchids do not show unusual ${ }^{13} \mathrm{C}$ enrichment, these orchids are usually considered autotrophic. Yet, this view has recently been questioned based on data that suggested orchid incorporation of organic matter issuing from a rhizoctonia source. Firstly, 'autotrophic' orchids still have minor deviations, either positive or negative, in ${ }^{13} \mathrm{C}$ abundance as compared to autotrophic species, coupled with high ${ }^{15} \mathrm{~N}$ enrichment and high $\mathrm{N}$ content (Hynson et al., 2013; Selosse and Martos, 2014). Secondly, they display higher ${ }^{2} \mathrm{H}$ enrichment than autotrophic plants, a feature that may be explained if orchids receive ${ }^{2} \mathrm{H}$-rich organic matter from their mycorrhizal fungi (Gebauer et al., 2016). Yet, despite evidence that rhizoctonia fungi are widespread orchid partners that support the nutrition during germination, they never fully support achlorophyllous adult orchids at maturity (see review in Dearnaley et al., 2012). Whenever a species from one of the families of rhizoctonia fungi was found to support full mycoheterotrophy, it belonged to species that by exception had ectomycorrhizal abilities (e.g., Bougoure et al., 2010; Yagame et al., 2012). Thus, the amount of $\mathrm{C}$ provided by rhizoctonia fungi to orchids may be limited by their specific saprotrophic or endophytic ecology (Selosse and Martos, 2014) and the occurrence of mixotrophy in rhizoctoniaassociated orchids remains debated.

It has been suggested that the emergence of substantial levels of heterotrophy detectable by ${ }^{13} \mathrm{C}$ abundance is linked to a shift from rhizoctonia fungi, the ancestral orchids' partners, to ectomycorrhizal fungi, and that this shift has occurred frequently in orchid evolution (Hynson et al., 2013). Some orchid genera contain species with both types of nutritional syndrome and therefore support evidence for this evolutionary shift. Typical examples are species within Cymbidium (Ogura-Tsujita et al., 2012) or Neottia (Těšitelová et al., 2015). However, with the use of next-generation sequencing that considerably enhanced the depth of detection of fungal communities (Waud et al., 2014), there is increasing evidence that some ectomycorrhizal fungi can occur in rhizoctonia-associated orchids, and vice-versa (Jacquemyn et al., 2014, 2016a; Oja et al., 2015; Těšitelová et al., 2015). Clearly, this challenges the distinction between the two syndromes in terms of associated fungi.

In this study, we investigated the relationship between nutritional syndromes and the composition of mycorrhizal communities in a range of terrestrial green orchids that commonly co-occur in wet dune slacks. Dune slacks are linear depressions that lay close to sea level in coastal dune systems and are characterized by high irradiance levels. They often undergo a successional series. Young dune slacks are generally speciespoor (Bossuyt et al., 2003), but as they age, the vegetation cover increases toward completion and a true soil begins to develop. Previous molecular investigations have shown that dune slacks contain very diverse mycorrhizal communities in the soil (Geml et al., 2014). More specifically, to assess whether each orchid species from dune slacks could be assigned to a definite fungal community and nutritional syndrome, we combined detailed assessments of the mycorrhizal communities associating with each orchid species with isotopic studies. Finally, we investigated the correlation between the dominant type of mycorrhizal fungi and the level of heterotrophy as detected by ${ }^{13} \mathrm{C}$ and $\mathrm{N}$ abundance.

\section{MATERIALS AND METHODS}

\section{Study System}

Molecular and isotopic data were collected from seven orchid species that co-occurred in two coastal dune slacks along the Belgian coast (Ter Yde: $51^{\circ} 8^{\prime} 18^{\prime \prime} \mathrm{N}-2^{\circ} 42^{\prime} 14^{\prime \prime}$ E; Westhoek: $\left.51^{\circ} 5^{\prime} 16^{\prime \prime} \mathrm{N}-2^{\circ} 33^{\prime} 48^{\prime \prime} \mathrm{E}\right)$. Both sampling sites were devoid of trees and had similar, high light conditions. The sampled orchid species included two Epipactis species (E. neerlandica and 
E. palustris), three Dactylorhiza species (D. fuchsii, D. incarnata, and D. praetermissa), Herminium monorchis, and Liparis loeselii.

\section{Mycorrhizal Sampling and Analyses}

To assess differences in orchid mycorrhizal communities between the seven species, young roots of five replicate individuals were collected for each species in the most central part of each of the study populations in summer 2015. After roots were carefully excavated from the soil, they were transported to the laboratory and immediately surface sterilized (30 s submergence in 1\% sodium hypochlorite, followed by three $30 \mathrm{~s}$ rinse steps in sterile distilled water). Mycorrhizal association was confirmed by detection of peloton structures using thin cross sections of orchid roots. These sections were gently cleared in hot alkali, stained using Trypan blue, and viewed with interference contrast microscopy (Brundrett et al., 1990). Subsequently, DNA was extracted from $0.5 \mathrm{~g}$ mycorrhizal root fragments using the UltraClean Plant DNA Isolation Kit as described by the manufacturer (Mo Bio Laboratories, Inc., Solana Beach, CA, United States) and 10 times diluted afterward. Amplicon libraries were created using the broad-spectrum internal transcribed spacer (ITS) primers ITS3 (5'-GCATCGATGAAGAACGCAG-3') and ITS4OF (5'-TTACTAGGGGAATCCTTGTT- $3^{\prime}$ ) (White et al., 1990; Taylor and McCormick, 2008). This primer pair has been shown to amplify substantial diversity of sequences and to detect a variety of orchid-associating mycorrhizal families (Waud et al., 2014). All samples (65 in total) were assigned unique MID (Multiplex Identifier) barcode sequences according to the guidelines for 454 GS-FLX Lib-L sequencing.

Polymerase chain reaction (PCR) amplification was performed in duplicate in a $25 \mu \mathrm{l}$ reaction volume containing $0.15 \mathrm{mM}$ of each dNTP, $0.5 \mu \mathrm{M}$ of each primer, $1 \mathrm{U}$ Titanium Taq DNA polymerase, 1X Titanium Taq PCR buffer (Clontech Laboratories, Palo Alto, CA, United States), and $1 \mu \mathrm{l}$ of a 10-times diluted DNA extract. PCR conditions were as follows: initial denaturation of $2 \mathrm{~min}$ at $94^{\circ} \mathrm{C}$ followed by 30 cycles of $45 \mathrm{~s}$ at $94^{\circ} \mathrm{C}, 45 \mathrm{~s}$ at $59^{\circ} \mathrm{C}$, and $45 \mathrm{~s}$ at $72^{\circ} \mathrm{C}$. After resolving the amplicons by agarose gel electrophoresis, amplicons within the appropriate size range ( $\sim 250-500 \mathrm{bp})$ were cut from the gel and purified using the Qiaquick gel extraction kit (Qiagen, Hamburg, Germany). Purified dsDNA amplicons were quantified using the Qubit fluorometer (Invitrogen) and pooled in equimolar quantities of $1.00 \mathrm{E}+10$ molecules per sample. This yielded two amplicon libraries, each representing one of the two PCR replicates. The quality of the amplicon libraries was assessed using an Agilent Bioanalyzer 2100 and high sensitivity DNA chip (Agilent Technologies, Waldbronn, Germany). Each amplicon library was loaded onto $1 / 8$ th of a 454 Pico Titer Plate (PTP). Pyrosequencing was performed using the Roche GS FLX instrument and Titanium chemistry according to the manufacturer's instructions (Roche Applied Science, Mannheim, Germany).

\section{Stable Isotope Analyses}

Samples for isotopic analysis were collected from the same set of orchids at Ter Yde and Westhoek in summer 2015, at the same time that roots were collected for mycorrhizal analyses. At Ter Yde, we sampled Epipactis palustris, E. neerlandica and Dactylorhiza praetermissa, and at Westhoek, in addition to the two first previous species, we sampled Dactylorhiza fuchsii, D. incarnata, H. monorchis, and L. loeselii. At both sites, we also sampled representatives of several surrounding nonorchid autotrophic plants (see names in Figure 4). For each species, we collected five leaves, each from different plants. Samples were ground in $2 \mathrm{~mL}$ Eppendorf tubes in a ball mill (MM200, Retsch Gmbh, Haan, Germany) and analyzed for total $\mathrm{N}$ concentration, as well as ${ }^{13} \mathrm{C} /{ }^{12} \mathrm{C}$ and ${ }^{15} \mathrm{~N} /{ }^{14} \mathrm{~N}$ ratios using an elemental analyser (EA) coupled to a ThermoFinnigan DeltaV Advantage Continuous-Flow Isotope-ratio mass spectrometer, and expressed as $\delta$-values (Hynson et al., 2013). Isotope values were calibrated using internal calibrated standards (EDTA and ammonium oxalate). The standard deviations of the replicated standard samples were $0.029 \% 0$ for ${ }^{13} \mathrm{C}$ and $0.215 \%$ for ${ }^{15} \mathrm{~N}$.

\section{Data Analyses \\ Fungal Diversity}

Sequences obtained from 454 pyrosequencing were assigned to the appropriate sample based on both barcode and primer sequences, allowing zero discrepancies, and were subsequently trimmed from the barcodes and primers using CUTADAPT 1.0 (Martin, 2011). Sequences were trimmed based on a minimum Phred score of 30 (base call accuracy of 99.9\%) averaged over a $50 \mathrm{bp}$ moving window. Sequences with ambiguous base calls or homopolymers longer than eight nucleotides were rejected, as were chimeric sequences detected by the UCHIME chimera detection program (de novo algorithm) (Edgar et al., 2011). Sequences which passed all quality control procedures were used as the basis for all further analyses. Minimum and maximum sequence lengths were set to 250 and 500 nucleotides, respectively. For further analysis, sequence data obtained for both PCR replicates were combined for each sample.

Operational taxonomic units (OTUs) were determined using UPARSE (Edgar, 2013), with sequences exceeding 97\% sequence homology being clustered into the same OTU (Jacquemyn et al., 2015, 2016a,b; Oja et al., 2015). Global singletons and global doubletons (i.e., OTUs representing only one or two sequences in the whole dataset) were removed from further analysis since it has been shown that this improves the accuracy of diversity estimates (Ihrmark et al., 2012; Waud et al., 2014). The remaining OTUs were assigned taxonomic identities to the highest taxonomic rank possible based on BLAST (Altschul et al., 1990) results of representative sequences (as indicated by UPARSE) using GenBank (Benson et al., 2008), including uncultured/environmental entries. Finally, we manually screened OTUs for possible orchid-associating mycorrhizal families based on the data provided in Table 12.1 in Dearnaley et al. (2012) and information of previously detected mycorrhizal fungi from the roots, germinating seeds and protocorms of various Epipactis and Dactylorhiza species and L. loeselii (Kristiansen et al., 2001; Bidartondo et al., 2004; Selosse et al., 2004; Bidartondo and Read, 2008; Ogura-Tsujita and Yukawa, 2008; Ouanphanivanh et al., 2008; Shefferson et al., 2008; 
Illyés et al., 2009; Bailarote et al., 2012; Těšitelová et al., 2012; Jacquemyn et al., 2012, 2016b; Waud et al., 2017). Only OTUs corresponding to known orchid-associating mycorrhizal families were retained for further analysis. No previous data were available for H. monorchis.

\section{Fungal Community Composition}

Based on presence-absence data of the observed orchid mycorrhizal fungi in each of the sampled individuals, the fungal community composition associating with the different orchid species was visualized by non-metric multidimensional scaling (NMDS) using the Bray-Curtis coefficient as distance measure in the $\mathrm{R}$ software package 'vegan' (Oksanen et al., 2013). To test the hypothesis that the mycorrhizal communities differed between the sampled orchid species, we performed permutational analysis of variance (PERMANOVA; Anderson, 2001) using the 'adonis' function in the software package 'vegan' (Oksanen et al., 2013). Finally, Species Indicator Analysis was used to investigate whether mycorrhizal fungi could be identified that were significantly associated with one of the investigated orchid species. The 'multipatt' function in the $\mathrm{R}$ package 'indicspecies' (De Cáceres et al., 2010) was used to define indicator species of both individual species and combinations of species.

\section{Isotope Signatures}

For species found at two different sites, a Student's $t$-test was used to test whether the mean $\delta^{13} \mathrm{C}$ or $\delta^{15} \mathrm{~N}$ differed between sites. Analysis of variance (ANOVA) was used to evaluate differences in mean $\delta^{13} \mathrm{C}, \delta^{15} \mathrm{~N}$, and $\% \mathrm{~N}$ among species from a given site. If the null hypothesis (no difference between means) was rejected, Tukey's honestly significant difference (HSD) test was used to make pairwise multiple comparisons of the means. The alpha type I error threshold was set at 0.05 . All statistical analyses were performed using the $\mathrm{R}$ environment for statistical computing (R Development Core Team, 2013).

\section{RESULTS}

\section{Mycorrhizal Diversity}

The quality-filtered pyrosequencing data set comprised 556 fungal OTUs (89900 sequences), of which 104 (64732 sequences $72.0 \%$ ) were assigned to putatively orchid mycorrhizal OTUs according to Dearnaley et al. (2012) and information from previous studies that detected mycorrhizal fungi from the roots and protocorms of these and related orchid species (Supplementary Table S1). Individual samples contained on average 996 sequences of putatively orchid mycorrhizal OTUs, although there was substantial variation between samples (minimum: 101, maximum: 5489). Representative sequences for each mycorrhizal OTU found in this study were submitted to GenBank under the Accession Numbers KY083558 - KY083678 and MF567576 - MF567600.

The majority of the detected fungi belonged to the Ceratobasidiaceae (8 OTUs, 20671 sequences) and Tulasnellaceae (10 OTUs, 9701 sequences) among rhizoctonia fungi, and ectomycorrhizal fungi from the Thelephoraceae (23 OTUs, 13297 sequences), Sebacinaceae (26 OTUs, 8420 sequences) and Inocybaceae (14 OTUs, 8261 sequences) (Figure 1). Besides, a number of other ectomycorrhizal taxa previously shown to associate with these orchid species were detected, including members of the Cortinariaceae (8 OTUs, 2709 sequences), Tuberaceae (1 OTU, 376 sequences), and Pezizaceae (4 OTUs, 97 sequences). Additionally, a number of ectomycorrhizal or possibly endophytic fungi belonging to the Psathyrellaceae, Tricholomataceae, and Russulaceae were only sporadically observed (Figure 1).

Mycorrhizal communities associating with each species were diverse (Figure 2) (average number of OTUs per species per population: $37.8 \pm 7.6$, range: $23-48$ ) and all sampled individuals associated with multiple fungi simultaneously. The relative abundances of the fungal genera differed between species (Figure 2). Members of the Tulasnellaceae and Ceratobasidiaceae were retrieved from all sampled species, but only in very low abundances in E. neerlandica and L. loeselii (Figure 2). Tulasnella fungi were the dominant community members of Dactylorhiza species, whereas members of the Ceratobasidiaceae fungi dominated the mycorrhizal community associating with E. palustris (Figure 2), none of which clustered with ectomycorrhizal Ceratobasidiaceae taxa (sensu Veldre et al., 2013). Members of the Inocybaceae reached high relative abundances in L. loeselii and E. neerlandica and to a lesser extent in $H$. monorchis. Tuber reached high relative abundances in E. neerlandica, but was absent in all other species. Finally, members of the Sebacinaceae reached high relative abundances in E. neerlandica, whereas members of the Thelephoraceae had the highest relative abundances in L. loeselii.

Because Tulasnella strains have very derived ITS sequences (Dearnaley et al., 2012), additional analyses were performed using primers specifically designed for ITS detection of other Tulasnella species, in particular Tulasnella calospora. This strain appeared to be a major fungal associate in L. loeselii (Ouanphanivanh et al., 2008; Illyés et al., 2009) and was sporadically observed in Dactylorhiza (Jacquemyn et al., 2012, 2016b). However, while these primers successfully detected positive controls, the Liparis and Dactylorhiza root samples displayed no detectable strains of the T. calospora clade (Supplementary Figure S1).

The NMDS ordination showed that the investigated orchid species associated with distinctive mycorrhizal communities (Figure 3). The mycorrhizal communities associating with E. neerlandica and L. loeselii were clearly different from the other species, which tended to cluster together in the central part of the plot. The PERMANOVA analysis confirmed that community composition of mycorrhizal fungi differed significantly between the investigated orchid species $\left(R^{2}=0.34\right.$, pseudo- $F=3.81$, $P<0.001)$. Species Indicator Analysis revealed 24 indicator species. Dactylorhiza species were significantly associated with Tulasnella spp. (members of the rhizoctonias). E. neerlandica was significantly associated with ectomycorrhizal Tuber, Inocybe and several Thelephora OTUs, whereas rhizoctonia Ceratobasidium was a significant indicator species for E. palustris. Finally, L. loeselii significantly associated with several ectomycorrhizal Thelephora and Inocybe OTUs. 

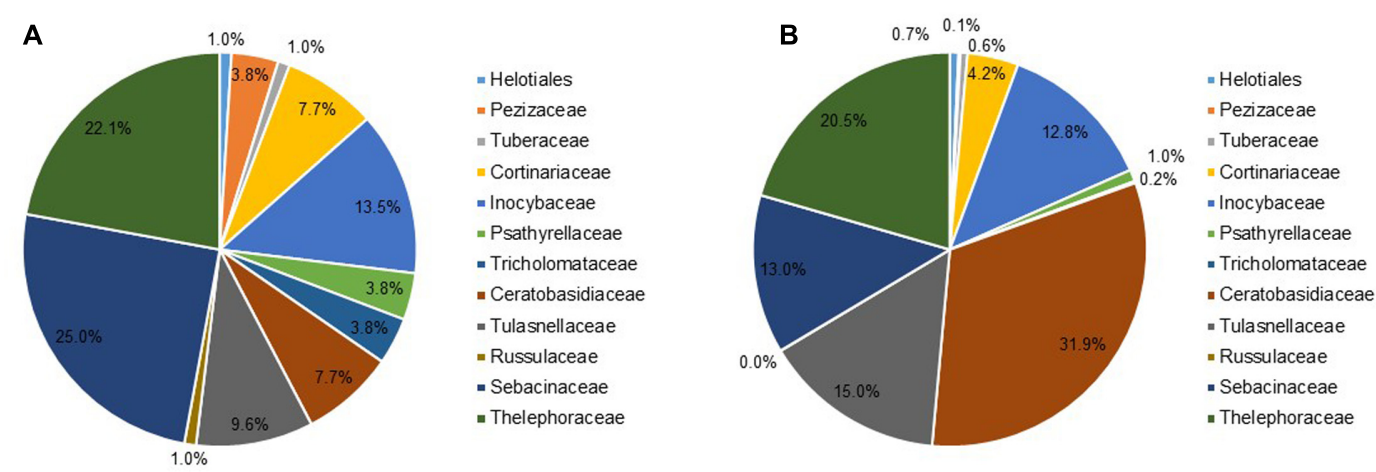

FIGURE 1 | Frequency distribution of (A) the number of OTUs and (B) the number of sequences for the different mycorrhizal families found associating with the seven orchid species (Dactylorhiza fuchsii, D. incarnata, D. praetermissa, Epipactis neerlandica, E. palustris, Herminium monorchis, and Liparis loeselii) investigated in this study.

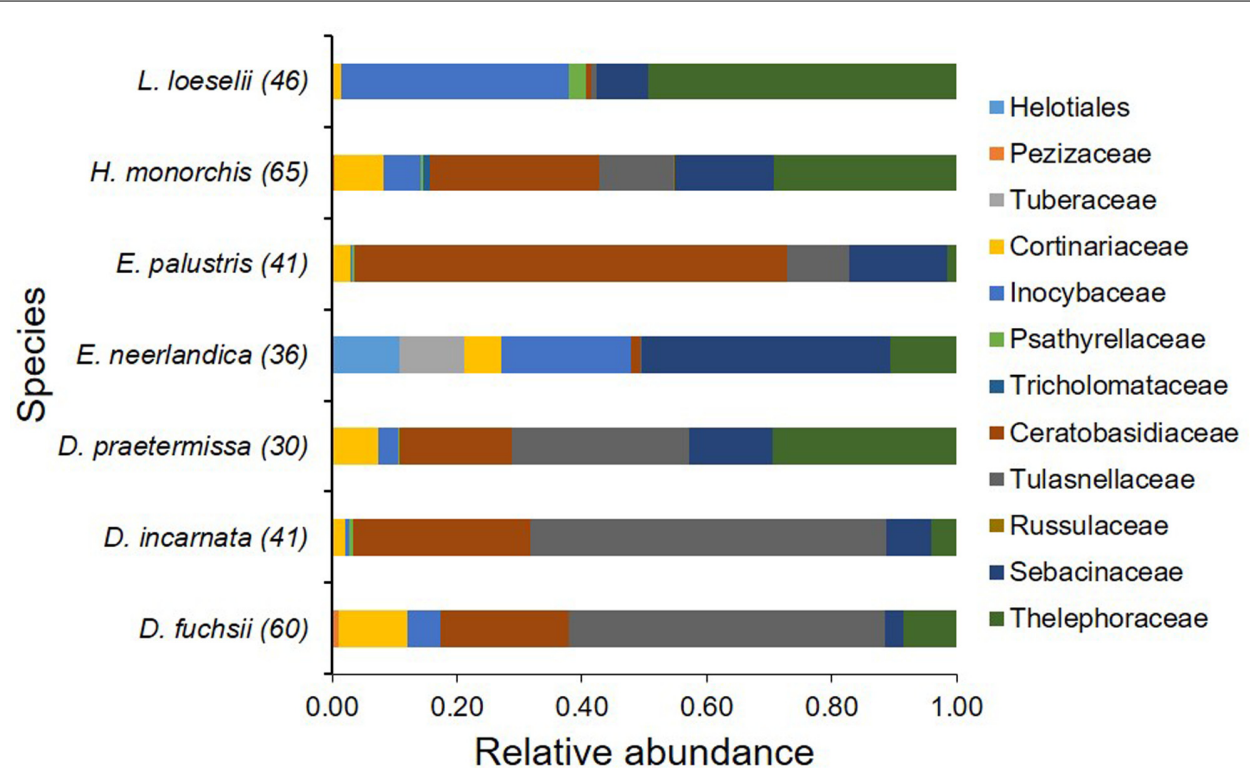

FIGURE 2 | Relative abundance of orchid mycorrhizal families associating with the seven orchid species that co-occur in dune slack communities. Relative abundance was calculated as the proportion of DNA sequences in each species assigned to each fungal family. The number of OTUs retrieved for each species is given between brackets.

\section{Isotope and Total $\mathbf{N}$ Analyses of Coexisting Orchids at Westhoek and Ter Yde}

At both sites, E. neerlandica was significantly more enriched in ${ }^{13} \mathrm{C}$ and ${ }^{15} \mathrm{~N}$ than all other species $(P<0.001$ for all comparisons), supporting a mixotrophic nutrition (Figure 4). $\delta^{13} \mathrm{C}$ values for the species collected at the two sites did not differ significantly (namely for $E$. neerlandica, $P=0.084$; E. palustris, $P=0.227$; and Rubus fruticosus agg., $P=0.342) . \delta^{15} \mathrm{~N}$ values for E. neerlandica were significantly higher at Westhoek $(6.48 \pm 0.40$; mean \pm standard deviation) than at Ter Yde $(4.57 \pm 0.21 ; P<0.001)$, whereas E. palustris showed lower values at Westhoek $(-3.91 \pm 0.20)$ compared to Ter Yde $(-2.67 \pm 0.22$; $P<0.001$ ), while $R$. fruticosus agg. had similar values at both sites
$(P=0.365)$. Regarding autotrophic references, Prunella vulgaris at Westhoek had very low $\delta^{13} \mathrm{C}(-32.01 \pm 0.19$; Figure 4A) compared to the mean value for other autotrophic species $(-28.98 \pm 0.75)$. At Westhoek, all orchids except E. neerlandica were depleted in ${ }^{13} \mathrm{C}$ relative to the autotrophic references except $P$. vulgaris $(P<0.05$ for all comparisons). Notable exceptions were $D$. fuchsii and E. palustris that were not distinguishable from Oenothera biennis $(P=0.616 ; P=1$; Figure $4 \mathrm{~A})$. At Ter Yde, all orchids besides $E$. neerlandica were either depleted (compared to Eupatorium cannabinum and R. fruticosus agg., $P<0.05$ for all comparisons) or enriched in ${ }^{13} \mathrm{C}$ (compared to Senecio vulgaris, $P<0.05$ for both comparisons; Figure 4B) or showed no difference in ${ }^{13} \mathrm{C}$ (compared to Leontodon sp., $P>0.05$ for both comparisons). As for ${ }^{15} \mathrm{~N}$, the orchids outside 


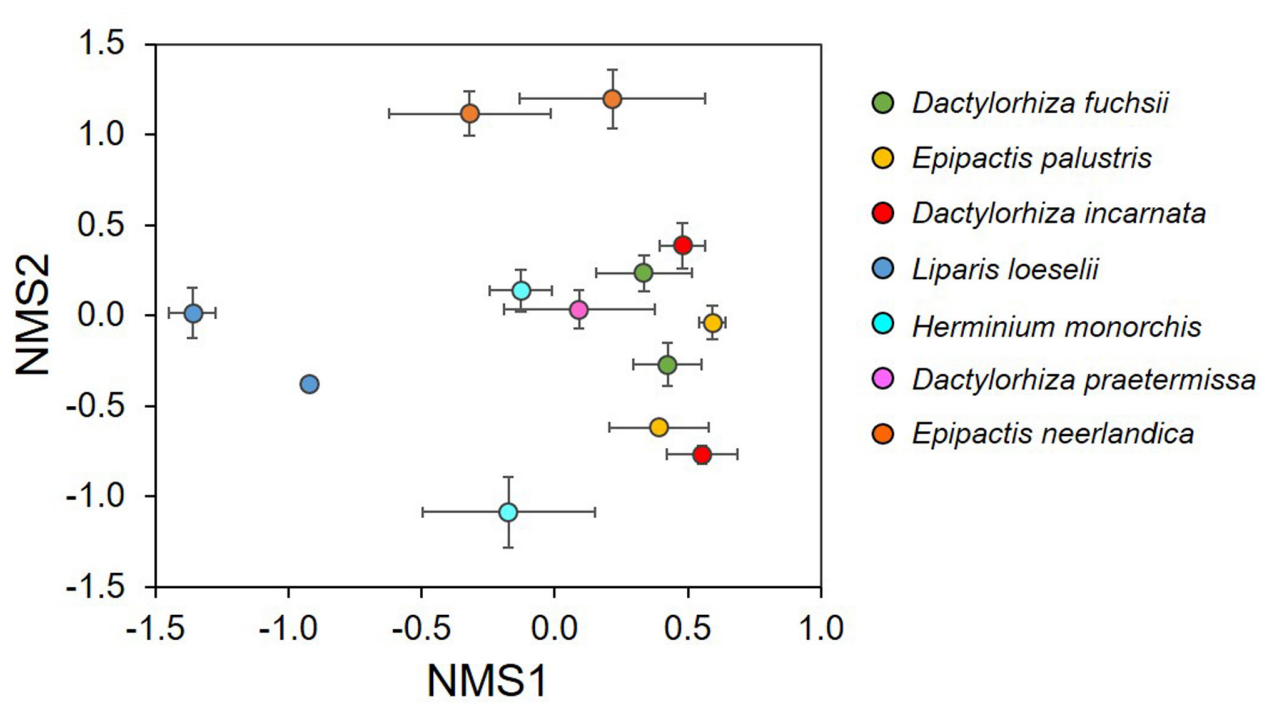

FIGURE 3 | Non-metric multidimensional scaling (NMDS) plot illustrating differences in mycorrhizal communities between seven orchid species that co-occur in dune slack communities. Each data point represents the average scores of five individual plants for each species and population.

E. neerlandica had higher $\delta^{15} \mathrm{~N}$ than most of the autotrophic references ( $P<0.05$ for all comparisons) at both sites; the only exceptions were D. incarnata and H. monorchis at Westhoek that were not distinguishable from O. biennis and Salix repens for the former $(P=0.121 ; P=0.998)$ and Salix sp. for the latter $(P=1)$.

Considering total $\mathrm{N}$ concentrations, the orchids fell in three distinct groups at Westhoek (Figure 5A): E. neerlandica and L. loeselii had the highest $\mathrm{N}$ concentrations $(P<0.001$ for all comparisons with other species); D. fuchsii and E. palustris had intermediate $\mathrm{N}$ concentrations $(P<0.01$ for all comparisons with other species); and all other orchids did not significantly differ from most autotrophic non-orchid species $(P>0.05$ for all comparisons with other species except $O$. biennis). The situation was similar at Ter Yde with E. neerlandica having the highest $\mathrm{N}$ concentration $(P<0.001$ for all comparisons; Figure 5B), E. palustris having intermediate $\mathrm{N}$ concentrations $(P<0.001$ for all comparisons), whereas $D$. praetermissa and autotrophic references had similar $\mathrm{N}$ concentrations $(P>0.05$ for all comparisons) lower than those of the two former species. Overall, all orchids tended to be enriched in ${ }^{15} \mathrm{~N}$ compared to surrounding autotrophic reference plants and four out of seven had higher total $\mathrm{N}$ concentrations, but only E. neerlandica also displayed the ${ }^{13} \mathrm{C}$ enrichment characterizing mixotrophy.

\section{DISCUSSION}

\section{Rhizoctonia versus Ectomycorrhizal Fungi: A Continuum of Orchid-Fungus Associations in Dune Slacks}

Our results showed that different orchid species co-occurring within dune slacks associated with diverse fungal communities. These fungi encompassed true rhizoctonia fungi (sensu Dearnaley et al., 2012), namely Tulasnellaceae and Ceratobasidiaceae (Serendipitaceae were absent), as well as various ectomycorrhizal clades (Thelephoraceae, Sebacinaceae, Inocybaceae, Tuberaceae, and Pezizaceae). The latter are likely supported by surrounding willows (Salix repens), which are ectomycorrhizal hosts to these taxa in dune ecosystems (Geml et al., 2014; Boonen et al., 2015) and which can provide them carbon. Their abundance in terms of reads and OTUs, given that they do not belong to usual contaminant fungi in soil samples, suggests that their presence has a true biological meaning. In E. neerlandica at least, the mycorrhizal status of these taxa can be supported since this species is phylogenetically close to, although ecologically isolated from E. helleborine (Jacquemyn et al., 2017). The latter commonly associates with ectomycorrhizal fungi (Bidartondo et al., 2004; Ogura-Tsujita and Yukawa, 2008; Těšitelová et al., 2012). Moreover, its isotopic values (see below) suggest that it belongs to mixotrophic species that receive organic matter from ectomycorrhizal fungi. In L. loeselii, the absence of rhizoctonia fungi also suggests that ectomycorrhizal fungi are the orchid's mycorrhizal partners.

Surprisingly, we did not observe a clear separation between orchids harboring rhizoctonia and ectomycorrhizal fungi, but rather a 'spectral' continuum of mycorrhizal communities was found, challenging the idea of a strict dichotomy between these two types of orchids. Our molecular analyses showed that all investigated species associated with both rhizoctonia and ectomycorrhizal fungi, although the prevalence of each fungal guild differed among species. At one extreme, E. neerlandica was nearly devoid of rhizoctonia fungi, whereas L. loeselii was very poor in rhizoctonia fungi; the same trend is also supported by analyses of this species at other sites (Waud et al., 2017). This trend contrasts with previous results from fen habitats in Hungary (Illyés et al., 2005, 2009), perhaps because the latter were obtained after in vitro isolation of the fungus: this procedure 

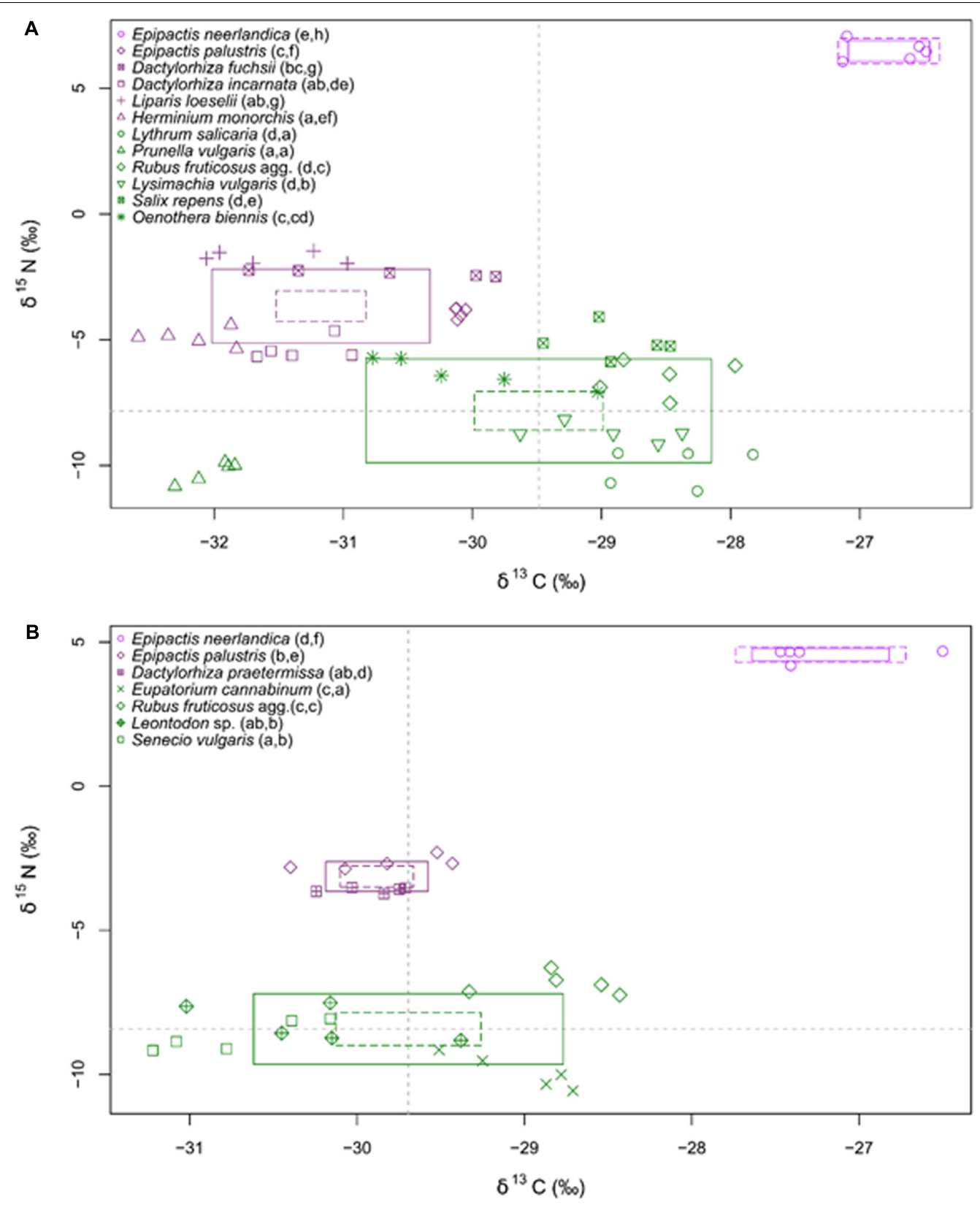

FIGURE $4 \mid \delta^{13} \mathrm{C}$ and $\delta^{15} \mathrm{~N}$ values of plants at Westhoek (A) and Ter Yde (B). Values for autotrophic non-orchid species are in green, and for orchid species in violet (with E. neerlandica in pink violet); $n=5$ replicates per species. The boxes show the 95\% confidence interval (dotted line) and standard deviation (continuous line) for each category. The gray dotted lines indicate the mean $\delta^{13} \mathrm{C}$ and $\delta^{15} \mathrm{~N}$ values for non-orchids autotrophs. Different letters in brackets following the names indicate significantly different values for, respectively, $\delta^{13} \mathrm{C}$ and $\delta^{15} \mathrm{~N}(P<0.05)$.

often screens against slow-growing ectomycorrhizal fungi. At the other extreme, Dactylorhiza spp. predominantly associated with rhizoctonia fungi, which largely supports previous works (e.g., Rasmussen, 1995; Kristiansen et al., 2001; Bidartondo et al., 2004; Shefferson et al., 2008; Bailarote et al., 2012; Jacquemyn et al., 2012, 2016b). E. palustris also showed a preference for rhizoctonia fungi, mainly fungi from the Ceratobasidiaceae and to a lesser extent from the Tulasnellaceae (Bidartondo et al., 2004; Jacquemyn et al., 2016a). An intermediate situation where both fungal guilds were present was found in $H$. monorchis (whose mycorrhizal fungi were never studied previously to the best of our knowledge; Rasmussen, 1995).

The presence of ectomycorrhizal fungi in rhizoctoniaassociated orchids has only been reported sporadically before the rise of high-throughput barcoding methods (e.g., Kristiansen et al., 2001; Shefferson et al., 2007; Jacquemyn et al., 2010, 2011; Liebel et al., 2015; Těšitelová et al., 2015) and it was suggested that their presence should not be neglected in 


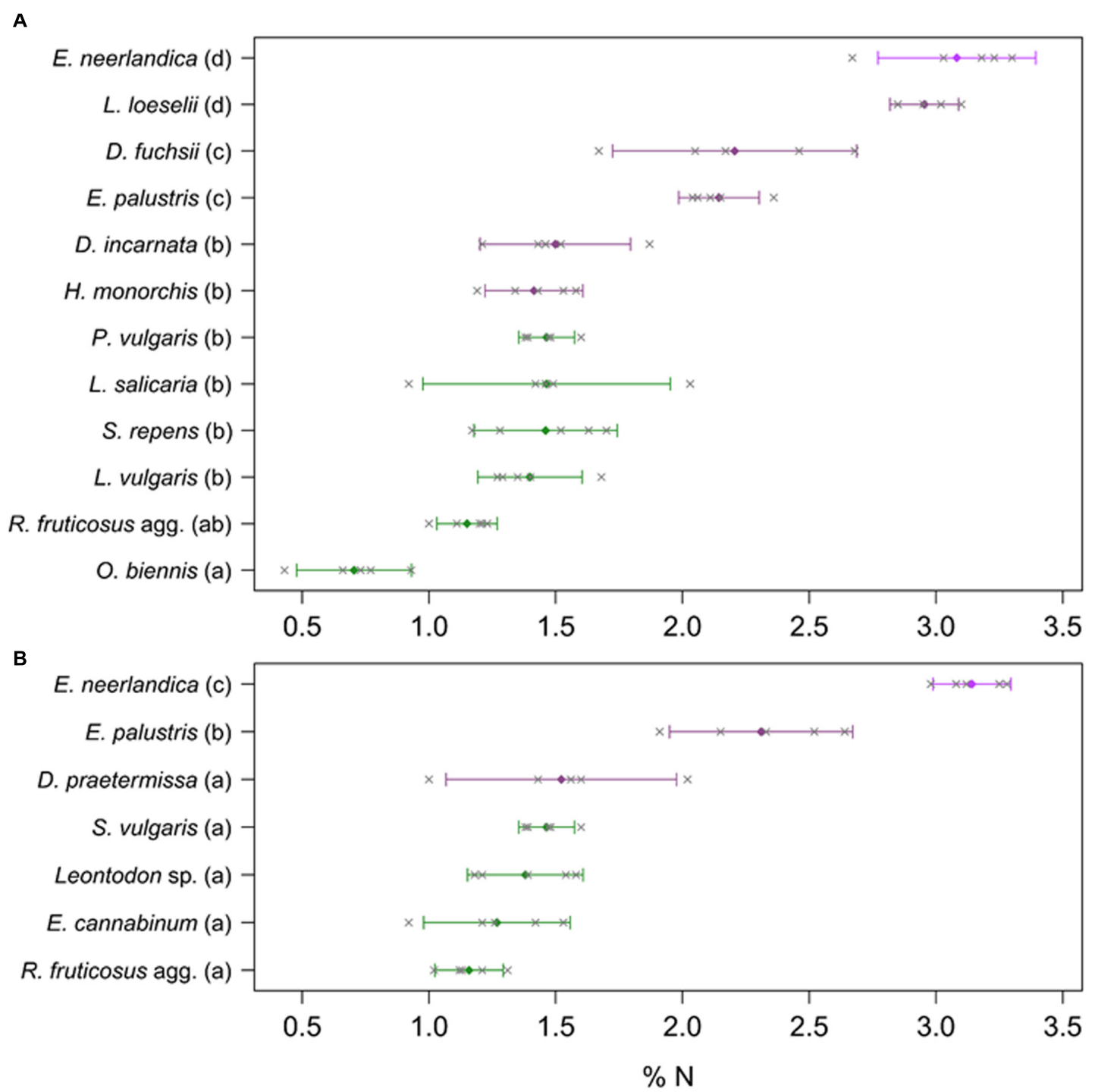

FIGURE 5 | Total N content of plants at Westhoek (A) and Ter Yde (B). Non-orchids are in green and orchids are in violet (with $E$. neerlandica in pink violet); $n=5$ replicates per species. Colored diamonds represent mean values whereas gray crosses show the five corresponding measures. Bars represent $95 \%$ confidence intervals; different letters indicate statistically significant differences $(P<0.05)$.

analyses of partner diversity (Selosse et al., 2010). The rise of next-generation sequencing, which significantly enhanced the sensitivity of detection and the ability to handle samples that are colonized by multiple fungi, confirmed this trend (e.g., Jacquemyn et al., 2014, 2015; Oja et al., 2015). Still, the exact interaction of ectomycorrhizal fungi with rhizoctoniaassociated orchids, in terms of root (or even cell) colonization, and their functional importance remains unclear. It can be questioned whether they are simple intercellular endophytes or whether they form intracellular pelotons similar to true mycorrhizal fungi in orchids. More detailed microscopic and physiological investigations are now needed to investigate whether ectomycorrhizal fungi in rhizoctonia-associated orchids are simple root commensalists or whether they bring nutrients, as can be expected from their roles in mixotrophic orchid species that exclusively associate with them.

\section{The Guild of Fungal Associates Does Not Always Predict Nutrition Type}

Isotopic abundances showed that, although most orchids were enriched in ${ }^{15} \mathrm{~N}$ abundance and total $\mathrm{N},{ }^{13} \mathrm{C}$ enrichment was only present in E. neerlandica, supporting the idea that it was the only mixotrophic orchid species based on these features. This species is the only one that grows at the edges of dune slacks, where the water table is probably lower than in dune slacks, and it was mostly colonized by ectomycorrhizal fungi of the Thelephoraceae, Tuberaceae, and Inocybaceae. Thus, E. neerlandica perfectly fits the mixotrophic syndrome described in the introduction. At the opposite, D. fuchsii, D. incarnata 
and D. praetermissa, E. palustris and H. monorchis, with total $\mathrm{N}$ content and ${ }^{13} \mathrm{C}$ enrichment close to that of autotrophic non-orchid plants, fitted the syndrome of autotrophic orchids (see the possible reservations and current debates over the exact autotrophy in this syndrome in Introduction). Orchids that mostly associated with rhizoctonia fungi only tended to have slightly lower ${ }^{13} \mathrm{C}$ enrichments as compared to nonorchid plants (discussed below), suggesting that ectomycorrhizal fungi did not contribute massively to their carbon budget. This is especially true for $H$. monorchis that, in spite of a high abundance of ectomycorrhizal fungi, turned out to be even significantly depleted in $13 \mathrm{C}$ as compared to autotrophic nonorchid plants.

The situation was less clear for L. loeselii, which mainly associated with members of the Thelephoraceae and Inocybaceae, with minor and infrequent occurrence of rhizoctonia fungi (see also Waud et al., 2017). Although its total $\mathrm{N}$ content was similarly high to that of the mixotrophic E. neerlandica, it was not enriched in ${ }^{13} \mathrm{C}$, and was in this respect similar to the orchids that mostly associated with rhizoctonia fungi. L. loeselii mycorrhizal partners are normally enriched in ${ }^{13} \mathrm{C}$ as other ectomycorrhizal fungi (Kohzu et al., 1999), although we did not measure this in the investigated sites, so that no evidence for mixotrophy was found in $L$. loeselii. Thus, the investigated species set from dune slacks display a disconnection between the presence of ectomycorrhizal fungi and mixotrophy, as estimated from ${ }^{13} \mathrm{C}$ and total $\mathrm{N}$ enrichment.

\section{The Evolutionary Lability of Nutritional Syndromes in Orchids}

Our results further support previous results that have shown that E. palustris is autotrophic (Bidartondo et al., 2004; Hynson et al., 2013; Schiebold et al., 2017). The confirmation of autotrophy in E. palustris contrasts with the mixtrophy usually observed in other Epipactis spp. (Selosse et al., 2004; Bidartondo et al., 2004; Gonneau et al., 2014; see Hynson et al., 2013 for review). The genus Epipactis therefore represents another example of orchid genera that encompass both mixo- and autotrophic species, such as also observed in Cymbidium (Ogura-Tsujita et al., 2012) and Neottia (Těšitelová et al., 2015). These genera are relevant to study the shift to mixotrophy (since autotrophy is likely the ancestral state), and the possibility of reversions from mixo- to autotrophy.

Our data confirm previous reports that have shown the presence of ectomycorrhizal fungi in orchids that primarily associate with rhizoctonia-like fungi. Even if their exact role and influence remain unclear in autotrophic orchids, they may potentially indicate a first step in the evolution of mixotrophy assisted by ectomycorrhizal fungi, and suggest that the evolution to mixotrophy occurs in two consecutive steps. In such a scenario, ectomycorrhizal fungi would first gradually replace rhizoctonia fungi as mycorrhizal partners, without necessarily providing carbon, as suggested by the investigated L. loeselii. Subsequently, their indirect access to substantial nutrient resources from tree photosynthesis may allow the evolution of mixotrophy. However, whether ectomycorrhizal fungi in rhizoctonia-associated orchids represent a true predisposition remains to be assessed in other orchid lineages where mixotrophy has evolved. In this framework, the genus Epipactis represents, among others, an interesting taxon where the mix of species with different trophic modes and different symbionts, rhizoctonia and/or ectomycorrhizal fungi, offers possibilities to test this scenario thanks to phylogenetic reconstructions.

\section{CONCLUSION}

Overall, our data demonstrate that co-occurring orchid species have distinctive mycorrhizal communities and indicate that the association with rhizoctonia fungi versus ectomycorrhizal fungi is not an alternative, but rather a continuum between extremes that exists within a given ecosystem. Moreover, our combined analysis of isotopes and fungal communities revealed that the presence of ectomycorrhizal fungi does not entail evidence for mixotrophy, at least in terms of ${ }^{13} \mathrm{C}$ and $\mathrm{N}$ content, as shown by L. loeselii. There are thus intermediates between the two extreme syndromes, namely rhizoctonia-associated orchids, often considered autotrophic, versus mixotrophic orchids associated with ectomycorrhizal fungi. This questions whether a low level of colonization by ectomycorrhizal fungi in rhizoctonia-associated orchids may predispose to the evolutionary transition to an association with ectomycorrhizal fungi in some orchid phyla. Our results therefore call for a more precise understanding of the nature and physiological significance of ectomycorrhizal fungi present within rhizoctonia-associated orchids.

\section{AUTHOR CONTRIBUTIONS}

$\mathrm{HJ}, \mathrm{RB}$, and M-AS designed the experiment, $\mathrm{HJ}$ and $\mathrm{RB}$ performed the field work, MW performed the molecular analyses, FL, P-EC, and AR performed the isotope analyses, HJ, MW, and FL performed the statistical analyses, HJ and M-AS wrote the first draft of the manuscript, all authors read and approved the final draft.

\section{ACKNOWLEDGMENTS}

M-AS laboratories are supported by the 2015/18/A/NZ8/00149 grant funded by National Science Centre (Poland) and the Fondation Ars Cuttoli \& Paul Appell, under the umbrella of the Fondation de France. MW acknowledges funding from the European Research Council (ERC starting grant 260601 MYCASOR granted to HJ) and KU Leuven Onderzoeksraad.

\section{SUPPLEMENTARY MATERIAL}

The Supplementary Material for this article can be found online at: http://journal.frontiersin.org/article/10.3389/fpls.2017.01497/ full\#supplementary-material 
FIGURE S1 | Gel results from PCR analyses conducted for verification of Tulasnella species presence/absence in (A) Liparis loeselii and (B) Dactylorhiza root samples using an enhanced version of the Tulasnella specific primer combination for ITS (namely ITS1ngs/ITS4-Tul2, described in Oja et al., 2015). Similar results were obtained using the primer pair ITS1/ITS4-Tul (data not shown). Expected Tulasnella species band size range from 600 to $1200 \mathrm{bp}$ based on previous experiments. PCR reactions were conducted in duplicated $25 \mu \mathrm{l}$ reactions containing $5 \mathrm{ng}$ DNA extract, $1 \cup$ Titanium Taq (Takara, Bio, United States), 2 mM dNTPs, and $20 \mu \mathrm{M}$ primer combination ITS1ngs/ ITS4-Tul2. The amplification program was as follows: 2 min at $95^{\circ} \mathrm{C}$, followed by 30 cycles of $30 \mathrm{~s}$ at $95^{\circ} \mathrm{C}, 30 \mathrm{~s}$ at $55^{\circ} \mathrm{C}, 1 \mathrm{~min}$ at $72^{\circ} \mathrm{C}$ and a final step at $72^{\circ} \mathrm{C}$ for $10 \mathrm{~min}$. Duplicated PCR reactions were pooled and $5 \mu \mathrm{l}$ of pooled PCR product was checked for amplification by separation on $1.5 \%$ agarose gel. Lane components for (A) are as follows: MM, SmartLadder reference (Eurogentec, Belgium); Lane 1, negative control - no template DNA; Lane 2,

\section{REFERENCES}

Abadie, J. C., Puttsepp, U., Gebauer, G., Faccio, A., Bonfante, P., and Selosse, M.A. (2006). Cephalanthera longifolia (Neottieae, Orchidaceae) is mixotrophic: a comparative study between green and nonphotosynthetic individuals. Can. J. Bot. 84, 1462-1477. doi: 10.1111/j.1438-8677.2009.00252.x

Altschul, S. F., Gish, G. W., Miller, W., Myers, E. W., and Lipman, D. J. (1990). Basic local alignment search tool. J. Mol. Biol. 215, 403-410. doi: 10.1016/S00222836(05)80360-2

Anderson, M. J. (2001). A new method for non-parametric multivariate analysis of variance. Austral Ecol. 26, 32-46.

Bailarote, B. C., Lievens, B., and Jacquemyn, H. (2012). Does mycorrhizal specificity affect orchid decline and rarity? Am. J. Bot. 99, 1655-1665. doi: 10.3732/ajb. 1200117

Benson, D. A., Karsch-Mizrachi, I., Lipman, D. J., Ostell, J., and Wheeler, D. L. (2008). GenBank. Nucleic Acids Res. 36, 25-30. doi: 10.1093/nar/ gkm929

Bernard, N. (1899). Sur la germination du Neottia nidus-avis. Comptes rendus hebdomadaires des séances de l'académie des sciences. Paris 128, 1253-1255.

Bidartondo, M. I., Burghardt, B., Gebauer, G., Bruns, T. D., and Read, D. J. (2004). Changing partners in the dark: isotopic and molecular evidence of ectomycorrhizal liaisons between forest orchids and trees. Proc. R. Soc. B Biol. Sci. 271, 1799-1806. doi: 10.1098/rspb.2004.2807

Bidartondo, M. I., and Read, D. J. (2008). Fungal specificity bottlenecks during orchid germination and development. Mol. Ecol. 17, 3707-3716. doi: 10.1111/j. 1365-294X.2008.03848.x

Boonen, S., Kafserud, H., Carlsen, T., Blaalid, R., and Heiland, K. (2015). Mycorrhizal fungal communities in coastal sand dunes and heaths investigated by pyrosequencing analyses. Mycorrhiza 25, 447-456. doi: 10.1007/s00572-0140624- 1

Bossuyt, B., Honnay, O., and Hermy, M. (2003). An island biogeographical view of the successional pathway in wet dune slacks. J. Veg. Sci. 14, 781-788. doi: 10.1111/j.1654-1103.2003.tb02210.x

Bougoure, J. J., Brundrett, M. C., and Grierson, P. F. (2010). Carbon and nitrogen supply to the underground orchid, Rhizanthella gardneri. New Phytol. 186, 947-956. doi: 10.1111/j.1469-8137.2010.03246.x

Brundrett, M. C., Murase, G., and Kendrick, B. (1990). Comparative anatomy of roots and mycorrhizae of common Ontario trees. Can. J. Bot. 68, 551-578. doi: 10.1139/b90-076

Burgeff, H. (1909). Die Wurzpilze der Orchideen, ihre Kultur und ihr Leben in der Pflanze. Jena: G. Fisher.

Cameron, D. D., Johnson, I., Read, D. J., and Leake, J. R. (2008). Giving and receiving: measuring the carbon cost of mycorrhizas in the green orchid, Goodyera repens. New Phytol. 180, 176-184. doi: 10.1111/j.1469-8137.2008. 02533.x

De Cáceres, M., Legendre, P., and Moretti, M. (2010). Improving indicator species analysis by combining groups of sites. Oikos 119, 1674-1684. doi: 10.1111/j. 1600-0706.2010.18334.x

Dearnaley, J. W. D., Martos, F., and Selosse, M. A. (2012). "Orchid mycorrhizas: molecular ecology, physiology, evolution and conservation aspects," in Fungal Associations, ed. B. Hock (Berlin: Springer-Verlag), 207-230. negative fungal DNA control - Mortierella isabellina isolate UAMH 5163; Lane 3, positive control - Tulasnella calospora isolate CBS 573.83; Lanes 4-5, non-Tulasnella mycorrhizal control - Salix repens root samples; Lanes 6-15, Liparis loeselii root samples. Lane components for Dactylorhiza species (B) are as follows: MM, SmartLadder reference (Eurogentec, Belgium); Lane 1, negative control - no template DNA; Lane 2, negative fungal DNA control Mortierella isabellina isolate UAMH 5163; Lane 3, positive control - Tulasnella calospora isolate CBS 573.83; Lane 4, positive control - Tulasnella sp. isolate CBS 482.93; Lane 5, positive control - Tulasnella sp. isolate CBS 487.93; Lane 6, positive control - Tulasnella sp. isolate CBS 606.93; Lanes 7-8, non-Tulasnella mycorrhizal control - Salix repens root samples; Lanes 9-13, Dactylorhiza fuchsii (Westhoek) root samples; Lanes 14-18, Dactylorhiza incarnata (Westhoek) root samples; Lanes 19-23, Dactylorhiza fuchsii (Ter Yde) root samples; Lanes 24-28, Dactylorhiza incarnata (Ter Yde) root samples.

Dearnaley, J. W. D., Perotto, S., and Selosse, M. A. (2016). "Structure and development of orchid mycorrhizas," in Molecular Mycorrhizal Symbiosis, ed. F. Martin (Berlin: Springer-Verlag), 63-86. doi: 10.1002/9781118951 446.ch5

Edgar, R. C. (2013). UPARSE: highly accurate OTU sequences from microbial amplicon reads. Nat. Methods 10:996. doi: 10.1038/nmeth.2604

Edgar, R. C., Haas, B. J., Clemente, J. C., Quince, C., and Knight, R. (2011). UCHIME improves sensitivity and speed of chimera detection. Bioinformatics 27, 2194-2200. doi: 10.1093/bioinformatics/btr381

Gebauer, G., Preiss, K., and Gebauer, A. C. (2016). Partial mycoheterotrophy is more widespread among orchids than previously assumed. New Phytol. 211, 11-15. doi: 10.1111/nph.13865

Geml, J., Gravendeel, B., van der Gaag, K. J., Neilen, M., Lammers, Y., Raes, N., et al. (2014). The contribution of DNA barcoding to fungal conservation: diversity assessment, habitat partitioning and mapping red-listed fungi in protected coastal Salix repens communities in the Netherlands. PLoS ONE 9:e99852. doi: 10.1371/journal.pone.0099852

Girlanda, M., Segreto, R., Cafasso, D., Liebel, H. T., Rodda, M., Ercole, E., et al. (2011). Photosynthetic Mediterranean meadow orchids feature partial mycoheterotrophy and specific mycorrhizal associations. Am. J. Bot. 98, 1148-1163. doi: 10.3732/ajb.1000486

Girlanda, M., Selosse, M. A., Cafasso, D., Brilli, F., Delfine, S., Fabbian, R., et al. (2006). Inefficient photosynthesis in the Mediterranean orchid Limodorum abortivum is mirrored by specific association to ectomycorrhizal Russulaceae. Mol. Ecol. 15, 491-504. doi: 10.1111/j.1365-294X.2005.02770.x

Gonneau, C., Jersáková, J., de Tredern, E., Till-Bottraud, I., Saarinen, K., Sauve, M., et al. (2014). Photosynthesis in perennial mixotrophic Epipactis spp. (Orchidaceae) contributes more to shoot and fruit biomass than to hypogeous survival. J. Ecol. 102, 1183-1194. doi: 10.1111/1365-2745.12274

Hynson, N. A., Madesen, T. P., Selosse, M. A., Adam, I. K. U., Ogura-Tsujita, Y., Roy, M., et al. (2013). "The physiological ecology of mycoheterotrophy, in Mycoheterotrophy: The Biology of Plants Living on Fungi, ed. V. S. F. T. Merckx (Berlin: Springer-Verlag), 297-342.

Hynson, N. A., Schiebold, J. M.-I., and Gebauer, G. (2016). Plant family identity distinguishes patterns of carbon and nitrogen stable isotope abundance and nitrogen concentration in mycoheterotrophic plants associated with ectomycorrhizal fungi. Ann. Bot. 118, 467-479. doi: 10.1093/aob/ mcw119

Ihrmark, K., Bödeker, I. T. M., Cruz-Martinez, K., Friberg, H., Kubartova, A., Schenck, J., et al. (2012). New primers to amplify the fungal ITS2 region evaluation by 454-sequencing of artificial and natural communities. FEMS Microbiol. Ecol. 82, 666-677. doi: 10.1111/j.1574-6941.2012.01437.x

Illyés, Z., Halász, K., Rudnóy, S., Ouanphanivanh, N., Garay, T., and Bratek, Z. (2009). Changes in the diversity of the mycorrhizal fungi of orchids as a function of the water supply of the habitat. J. Appl. Bot. Food Qual. 83, 28-36.

Illyés, Z., Rudnoy, S., and Bratek, Z. (2005). Aspects of in situ, in vitro germination and mycorrhizal partners of Liparis loeselii. Acta Biol. Szeged. 49, 137-139.

Jacquemyn, H., Brys, R., Merckx, V. S. F. T., Waud, M., Lievens, B., and Wiegand, T. (2014). Co-existing orchid species have distinct mycorrhizal communities and 
display strong spatial segregation. New Phytol. 202, 616-627. doi: 10.1111/nph. 12640

Jacquemyn, H., Brys, R., Waud, M., Busschaert, P., and Lievens, B. (2015). Mycorrhizal networks and coexistence in species-rich orchid communities. New Phytol. 206, 1127-1134. doi: 10.1111/nph.13281

Jacquemyn, H., De Kort, H., vanden Broeck, A., and Brys, R. (2017). Immigrant and extrinsic hybrid seed inviability contribute to reproductive isolation between forest and dune ecotypes of Epipactis helleborine (Orchidaceae). Oikos. doi: 10.1111/oik.04329

Jacquemyn, H., Deja, A., De Hert, K., Bailarote, B. C., and Lievens, B. (2012). Variation in mycorrhizal associations with tulasnelloid fungi among populations of five Dactylorhiza species. PLoS ONE 7:e42212. doi: 10.1371/ journal.pone.0042212

Jacquemyn, H., Honnay, O., Cammue, B. P. A., Brys, R., and Lievens, B. (2010). Low specificity and nested subset structure characterize mycorrhizal associations in five closely related species of the genus Orchis. Mol. Ecol. 19, 4086-4095. doi: 10.1111/j.1365-294X.2010.04785.x

Jacquemyn, H., Merckx, V., Brys, R., Tyteca, D., Cammue, B. P. A., Honnay, O., et al. (2011). Analysis of network architecture reveals phylogenetic constraints on mycorrhizal specificity in the genus Orchis (Orchidaceae). New Phytol. 192, 518-528. doi: 10.1111/j.1469-8137.2011.03796.x

Jacquemyn, H., Waud, M., Lievens, B., and Brys, R. (2016a). Differences in mycorrhizal communities between Epipactis palustris, E. helleborine and its presumed sister species E. neerlandica. Ann. Bot. 118, 105-114. doi: 10.1093/ aob/mcw015

Jacquemyn, H., Waud, M., Merckx, V. S. F. T., Brys, R., Tyteca, D., Hedrén, M., et al. (2016b). Habitat-driven variation in mycorrhizal communities in the terrestrial orchid genus Dactylorhiza. Sci. Rep. 6:37182. doi: 10.1038/srep37182

Julou, T., Burghardt, B., Gebauer, G., Berveiller, D., Damesin, C., and Selosse, M.A. (2005). Mixotrophy in orchids: insights from a comparative study of green individuals and nonphotosynthetic individuals of Cephalanthera damasonium. New Phytol. 166, 639-653. doi: 10.1111/j.1469-8137.2005.01364.x

Kohzu, A., Yoshioka, T., Ando, T., Takahashi, M., Koba, K., and Wada, E. (1999). Natural $13 \mathrm{C}$ and $15 \mathrm{~N}$ abundance of field-collected fungi and their ecological implications. New Phytol. 144, 323-330. doi: 10.1046/j.1469-8137.1999.00508.x

Kristiansen, K. A., Taylor, D. L., Kjoller, R., Rasmussen, H. N., and Rosendahl, S. (2001). Identification of mycorrhizal fungi from single pelotons of Dactylorhiza majalis (Orchidaceae) using single-strand conformation polymorphism and mitochondrial ribosomal large subunit DNA sequences. Mol. Ecol. 10, 2089-2093. doi: 10.1046/j.0962-1083.2001.01324.x

Liebel, H. T., Bidartondo, M. I., and Gebauer, G. (2015). Are carbon and nitrogen exchange between fungi and the orchid Goodyera repens affected by irradiance? Ann. Bot. 115, 251-261. doi: 10.1093/aob/mcu240

Martin, M. (2011). Cutadapt removes adapter sequences from high-throughput sequencing reads. EMBnet J. 17, 10-12. doi: 10.14806/ej.17.1.200

McCormick, M. K., and Jacquemyn, H. (2014). What constrains the distribution of orchid populations? New Phytol. 202, 392-400. doi: 10.1111/nph.12639

Merckx, V. S. F. T. (2013). "Mycoheterotrophy: an introduction," in Mycoheterotrophy: The Biology of Plants Living on Fungi, ed. V. S. F. T. Merckx (Berlin: Springer-Verlag), 297-342. doi: 10.1007/978-1-46145209-6

Ogura-Tsujita, Y., Yokoyama, J., Miyoshi, K., and Yukawa, T. (2012). Shifts in mycorrhizal fungi during the evolution of autotrophy to mycoheterotrophy in Cymbidium (Orchidaceae). Am. J. Bot. 99, 1158-1176. doi: 10.3732/ajb. 110046

Ogura-Tsujita, Y., and Yukawa, T. (2008). Epipactis helleborine shows strong preference towards ectomycorrhizal fungi with contrasting geographic distributions in Japan. Mycorrhiza 18, 331-338. doi: 10.1007/s00572-0080187-0

Oja, J., Kohout, P., Tedersoo, L., Kull, T., and Kõljalg, U. (2015). Temporal patterns of orchid mycorrhizal fungi in meadows and forests as revealed by 454 pyrosequencing. New Phytol. 205, 1608-1618. doi: 10.1111/nph.13223

Oksanen, J., Blanchet, F. G., Kindt, R., Stevens, H., Legendre, P., Wagner, H., et al. (2013). VEGAN: Community Ecology Package. R Package Version 2.1-43/r2893. Available at: http://R-Forge.R-project.org/projects/vegan/

Ouanphanivanh, N., Merényi, Z., Orczán, Á. K., Bratek, Z., Szigeti, Z., and Illyés, Z. (2008). Could orchids indicate truffle habitats? Mycorrhizal association between orchids and truffles. Acta Biol. Szeged. 52, 229-232.
R Development Core Team (2013). R: A Language and Environment for Statistical Computing. Vienna: R Foundation for Statistical Computing.

Rasmussen, H. N. (1995). Terrestrial Orchids: From Seed to Mycotrophic Plant. New York, NY: Cambridge University Press. doi: 10.1017/CBO978051152 5452

Roy, M., Gonneau, C., Rocheteau, A., Berveiller, D., Thomas, J. C., Damesin, C., et al. (2013). Why do mixotrophic plants stay green? A comparison between green and achlorophyllous orchid individuals in situ. Ecol. Monogr. 83, 95-117. doi: 10.1890/11-2120.1

Schiebold, J. M. I., Bidartondo, M. I., Karasch, P., Gravendeel, B., and Gebauer, G. (2017). You are what you get from your fungi: nitrogen stable isotope patterns in Epipactis species. Ann. Bot. 119, 1085-1095. doi: 10.1093/aob/ mcw265

Selosse, M.-A., Bocayuva, M. F., Kasuya, M. C. M., and Courty, P. E. (2016). "Mixotrophy in mycorrhizal plants: extracting carbon from mycorrhizal networks," in Molecular Mycorrhizal Symbiosis, ed. F. Martin (Berlin: SpringerVerlag). doi: 10.1002/9781118951446.ch25

Selosse, M.-A., Faccio, G., Scappaticci, G., and Bonfante, P. (2004). Chlorophyllous and achlorophyllous specimens of Epipactis microphylla (Neottieae, Orchidaceae) are associated with ectomycorrhizal septomycetes, including truffles. Microb. Ecol. 47, 416-426. doi: 10.1007/s00248-003-2034-3

Selosse, M.-A., and Martos, F. (2014). Do chlorophyllous orchids heterotrophically use mycorrhizal fungal carbon? Trends Plant Sci. 19, 683-685.

Selosse, M.-A., Martos, F., Perry, B. A., Padamsee, M., Roy, M., and Pailler, T. (2010). Saprotrophic fungal symbionts in tropical achlorophyllous orchids: finding treasures among the 'molecular scraps'? Plant Signal. Behav. 5, 349-353. doi: $10.4161 / \mathrm{psb} \cdot 5.4 .10791$

Selosse, M.-A., and Roy, M. (2009). Green plants that feed on fungi: facts and questions about mixotrophy. Trends Plant Sci. 14, 64-70. doi: 10.1016/j.tplants. 2008.11.004

Shefferson, R. P., Kull, T., and Tali, K. (2008). Mycorrhizal interactions of orchids colonizing Estonian mine tailings hills. Am. J. Bot. 95, 156-164. doi: 10.3732/ ajb.95.2.156

Shefferson, R. P., Roy, M., Püttsepp, Ü., and Selosse, M.-A. (2016). Demographic shifts related to mycoheterotrophy and their fitness impacts in two Cephalanthera species. Ecology 97, 1452-1462. doi: 10.1890/151336.1

Shefferson, R. P., Taylor, D. L., Weiss, M., Garnica, S., McCormick, M. K., Adams, S., et al. (2007). The evolutionary history of mycorrhizal specificity among lady's slipper orchids. Evolution 61, 1380-1390. doi: 10.1111/j.15585646.2007.00112.x

Smith, S. E., and Read, D. J. (2008). Mycorrhizal symbiosis. Cambridge: Academic Press.

Taylor, D. L., and McCormick, M. K. (2008). Internal transcribed spacer primers and sequences for improved characterization of basidiomycetous orchid mycorrhizas. New Phytol. 177, 1020-1033. doi: 10.1111/j.1469-8137.2007. 02320.x

Těšitelová, T., Kotilínek, M., Jersáková, J., Joly, F.-X., Košnar, J., and Tatarenko, I. (2015). Two widespread green Neottia species (Orchidaceae) show mycorrhizal preference for Sebacinales in various habitats and ontogenetic stages. Mol. Ecol. 24, 1122-1134. doi: 10.1111/mec.13088

Těšitelová, T., Těšitel, J., Jěrsáková, J., Rihova, G., and Selosse, M.-A. (2012). Symbiotic germination capability of four Epipactis species (Orchidaceae) is broader than expected from adult ecology. Am. J. Bot. 99, 1020-1032. doi: 10.3732/ajb.1100503

Trudell, S. A., Rygiewicz, P. T., and Edmonds, R. L. (2003). Nitrogen and carbon stable isotope abundances support the myco-heterotrophic nature and host-specificity of certain achlorophyllous plants. New Phytol. 204, 882-889. doi: 10.1046/j.1469-8137.2003.00876.x

Veldre, V., Abarenkov, K., Bahram, M., Martos, F., Selosse, M.-A., Tamm, H., et al. (2013). Evolution of nutritional modes of Ceratobasidiaceae (Cantharellales, Basidiomycota) as revealed from publicly available ITS sequences. Fungal Ecol. 6, 256-268. doi: 10.1016/j.funeco.2013.03.004

Waud, M., Brys, R., Van Landuyt, W., Lievens, B., and Jacquemyn, H. (2017). Mycorrhizal specificity does not limit the distribution of an endangered orchid species. Mol. Ecol. 26, 1687-1701. doi: 10.1111/mec.14014

Waud, M., Busschaert, P., Ruyters, S., Jacquemyn, H., and Lievens, B. (2014). Impact of primer choice on characterization of orchid mycorrhizal 
communities using 454 pyrosequencing. Mol. Ecol. Resour. 14, 679-699. doi: 10.1111/1755-0998.12229

White, T. J., Bruns, T. D., Lee, S., and Taylor, J. W. (1990). “Amplification and direct sequencing of fungal ribosomal RNA genes for phylogenetics," in PCR Protocols: A Guide to Methods and Applications, eds M. A. Innis, D. H. Gelfand, J. J. Sninsky, and T. J. White (San Diego, CA: Academic Press), 315-322.

Yagame, T., Orihara, T., Selosse, M.-A., Yamato, M., and Iwase, K. (2012). Mixotrophy of Platanthera minor, an orchid associated with ectomycorrhizaforming Ceratobasidiaceae fungi. New Phytol. 193, 178-187. doi: 10.1111/j. 1469-8137.2011.03896.x
Conflict of Interest Statement: The authors declare that the research was conducted in the absence of any commercial or financial relationships that could be construed as a potential conflict of interest.

Copyright (c) 2017 Jacquemyn, Waud, Brys, Lallemand, Courty, Robionek and Selosse. This is an open-access article distributed under the terms of the Creative Commons Attribution License (CC BY). The use, distribution or reproduction in other forums is permitted, provided the original author(s) or licensor are credited and that the original publication in this journal is cited, in accordance with accepted academic practice. No use, distribution or reproduction is permitted which does not comply with these terms. 